\title{
Behaviour Management Plan for Elementary School Students
}

\author{
Sri Diana \\ Polytechnic ATI of Makassar \\ Jl. Sunu No. 220 Makassar \\ Sulawesi Selatan, Indonesia \\ Email: sridiana12@gmail.com
}

\begin{abstract}
The paper aims to explore the Glasser's Choice Theory, Neo Adlerian and Humanism Theory for the implementation of behavior management plan in elementary level. It starts with an explanation of some assumptions related to those theories. The paper then explains some prevention methods to manage students' disruptive behavior in the classroom. It also presents some interventions for inappropriate behavior in the class when the preventions are not effective. The paper provides several preventive approaches for minimizing misbehavior problems such as providing interesting and challenging activities, organizing classroom work and setting the physical classroom, developing communication between teachers and students, and also the involvement of parents. This paper also shows three effective interventions namely natural or logical consequences, time-out and contacting parents. The last, the paper also reveals that a partnership between teachers and parents can become strength for this behavior management plan but the use of time out is not effective because there is not a special room for implementing this intervention in the level of elementary.
\end{abstract}

Keywords-behaviour management plan, prevention, intervention, disruptive behaviour, time-out

\section{INTRODUCTION}

Teaching is a great professional for individuals who enjoy learning and helping others. However, we all believe that teaching or being a teacher is a challenge. One of the greatest responsibilities of teachers is managing their student behaviour. Disruptive behaviour in the class such as aggressive behaviour, is the major cause of stress and teachers sometimes leave their profession because of this reason. Due to this case, a behaviour management plan for elementary school students should be written in order to help teachers in managing their students' behaviour. The purpose of this plan is also to facilitate all elementary students can learn optimally. The private elementary school where this study is conducted has 30-40 students in each class. English is not the only subject taught in this class, they have mathematics teacher, religion teacher, sports teacher etc. There will be three models used in this paper such as Glasser's Choice Theory, Neo-Adlerian Theory and Humanism Theory. In this plan, some assumptions will be written based on those three theories and what is believed towards the models that can be useful for this behaviour management plan. Some preventive approaches by Glasser's Choice Theory, Neo-Adlerian and Humanism Theory will also be mentioned in this plan. However, it is also believed that some interventions should be preplanned too when the disruptive or inappropriate behaviour occurs in the class and the preventions do not work. The last, of course, this plan should be evaluated because there will be some strengths and also weaknesses in the implementation of this behaviour management plan.

\section{LITERATURE REVIEW}

All living creatures are born with needs. These basic needs drive all humans to achieve what they want. They can learn to satisfy these needs through responsible choices or irresponsible choices. People who make responsible and effective choices experience satisfied and pleasure. However, those who make irresponsible and less effective choices feel unsatisfied and frustrated. In school, it is believed that to improve the quality of students' work, we have to meet their basic needs. [1] For example, one of the most important needs is power. Students also need power at school to control their lives. However, in the traditional classroom, teachers show that they have control over their students' actions and lives. “... teachers were absolute decision-maker who had the right to tell students exactly what to do and how to do it". [2] ${ }^{(\mathrm{p} .58)}$ Consequently, students demonstrate power such as disobedience, stubbornness, argumentative etc.

Sense of belonging is also one of basic needs that has to be fulfilled in order to minimize disruptive behaviour. "Two of Adler's beliefs are that the central motivation of all humans is to belong and be accepted by others ... ". [3] ${ }^{(\mathrm{p} .5)}$ It is believed that individual including children need to feel that they belong, that they have a place in the family, in the school and in the community which are important for them

It is also believed that teachers have important roles in the classroom. They have to gain and maintain students' cooperation so that teachers enjoy satisfying teaching and their students get optimal learning activities. Moreover, being a teacher, we also have to teach our students how to distinguish between responsible and irresponsible behaviour. Teachers should introduce to students how to differentiate various of behaviour and the consequences if they break the rules. [4] However, Humanism theory also explains that a teacher is not only responsible to teach students how to think about the lessons and the result if they do not obey the rules. 


\section{PREVENTIONS}

Talking about behavioural difficulties, there are some approaches that can be effectively used in managing misbehaviour in the classroom. One factor that increases classroom misbehaviour is the failure of teachers to design an appropriate and interesting curriculum. Teachers should provide some activities where students are motivated and challenged in learning. As we know, students today are easily bored, so teachers have to be creative and innovative to meet students' needs.

Another approach that can prevent misbehaviour problems is developing classroom climate. At this point, teachers have to organize classroom work in order to facilitate learning process. "The physical design of classroom settings should be compatible with the type of activity taking place". [5] ${ }^{(\mathrm{P} .76)}$ This includes helping students in achieving the objectives that stated in curriculum and teachers' unit plans. Therefore, teachers should provide various learning activities in order to lighten the classroom. For example, developing classroom profiles. This activity will teach students to increase their self-esteem because in the process of activity all students have to write about themselves and after that exchange it with other students. [6]

Besides classroom work, the physical setting of classroom is also crucial in minimizing disruptive behaviour. Teachers can modify the classroom to facilitate the process of learning in the classroom, teachers have to consider carefully where and how students will be seated. For instance, in group work, teachers have to set the tables and chairs where students can be easily interacted and collaborated with other students. However, the desks and chairs should be changed for another type of activity such as U-shapes, in straight, rows or circles.

The next preventive method is communication. As we know that teaching is communication. Learning and teaching in the classroom predominantly take place through interpersonal communication between teachers and students. So, communication can not be ignored in preventing the increase of misbeahaviour problems in class. For example, teachers can be a mediator to help children when they get into conflicts with each other. This is the function of communication where teachers are able to be good listeners. Teachers can listen to the problem of both children and let them express their opinions and feelings. Thus, both students will be satisfied because they feel their opinions and feelings are accepted and respected by their teachers. Consequently, students will develop positive images towards their teachers and also increase their self-esteem. [7] Furthermore, to develop effective communication between teachers and students is through openness and trust. This can lead to high quality relationships. Apart from that, another mode of communication that is also very important in the classroom is the spoken word. This verbal communication is very prevalent in classroom communication. Therefore, teachers should consider carefully in using the spoken word in their classroom. To illustrate, a teacher asks a student to do something and expects the student to do it without asking again. Because she is busy with an individual student, so she asks another student who sits near the door to close it. She says "Steve, would you please shut the door?". The teacher expects him directly close the door and then return to his seat. After that, the teacher does not forget to follow with a "thank you" to Steve. "Teachers who use polite expressions signal the class that they respect the students and appreciate their help". $[8]^{(\text {P.63) }}$

In addition to some preventive methods above, another prevention that has to be considered is parental involvement. A study has shown that students will be more successful if their parents involve and support them at school. [9] It is strongly believed that most teachers will agree that students achieve better when there is a partnership between their parents and teachers, home and school. Contacting parents should not be limited to conversation about students' problems at school. However, parents also want to hear about their child's work and positive things about their child.

Therefore, school needs to find effective communication to achieve this. "Information may be in the form written language, videos, cassettes, or the spoken word". [10] ${ }^{(\mathrm{P} .43)}$ For instance, teachers should send a letter home before school begins in which they emphasize that they are enthusiastic about working with students and look forward having their children in class. In this letter, teachers can also mention about the goals, academic and behaviour expectations such as homework, grading policies and class requirements. Besides sending a letter home, using telephone communication is also possible. For example, one student has a problem in a class and teachers try not to make this become worst, so that it should be handled properly. This can attended once a month or once in two months and should be used as a media to get some ideas, suggestions and critiques from parents for the improvement of school.

\section{INTERVENTIONS}

Good behaviour management prioritizes to anticipate the type of behaviour problems begins in any groups. So, every teacher who develops a plan of action has at hands the means to react effectively to minimize the negative effect of students' misbehaviour in the class. However, if the problems behaviour still occur, so teachers should find a solution how to deal with these problems. Based on the three models such as Glasser's Choice theory, Neo-Adlerian theory and Humanism theory, three kinds of interventions will be applied in this plan they are using natural or logical consequences, time-out and contacting parents.

One off all, for instance, a child who refuses to eat goes hungry; a child who stays up late at night suffers from tiredness and feels sleepy at the next day. It is believed that using a natural consequence is also effective in handling irresponsible behaviour. Moreover, this consequence will teach students how to be responsible because they have learnt through their experiencing natural consequences. To apply this consequence, teachers do nothing; they just give 
students the information about the consequences of behaviour. It is believed that applying logical consequences are also important and useful besides natural consequences. Logical consequences emphasize on cause and effect link between the choice of behaviour and the consequence. For example, the case of a student who always comes late to class. Harry was often late arriving at class in the morning. His teacher always rebuked him, but the teacher still gave him the explanation. Because Harry did not change his behaviour and kept coming late so, his teacher decided to apply behaviour consequences. The next day when Harry arrived late again, the teacher ignored him and kept teaching the other students in the class. When Harry asked the teacher to explain it again, the teacher just told him that she did not give a second explanation about the tasks. She would detail the tasks after the class and he had to complete it in his own time. The case above shows that Harry has to accept the logical consequence from the inappropriate behaviour he has chosen. This consequence is related to the behaviour in which Harry always comes late to class. He has to be responsible to his choice. Now, it depends on him, keeps coming late but he has to stay after class to get details of the tasks or he tries to come on time.

Secondly, teachers can also use time out to decrease undesired behaviour. Applying time out means teachers send their misbehaviour student to another room. Teachers use time out only for students who behave disruptively, not for students who have educational problems like reading difficulties or a student who is not good at mathematics. For instance, a student who always screams very loudly in the class. In order to make him calm down, the teacher sends him to a time out room. After 1 or 2 minutes, the teacher will come and talk to him about what he has done in the class. If he promises to be cooperative, then he can join and participate in the class again. However, if the disruptive behaviour still exists and the student cannot be handled anymore so, teacher can inform his parents and let the student to stay home for a while. [11]

The last intervention in this management plan is contacting parents. This step can not be ignored because parents also have their rights to know if their child has a problem at school. At this point, teacher and parents have their own roles, teachers are responsible mostly at school while parents at home. Therefore, if there is a student experiences a problem at school, teachers should contact the student's parents and tell them about their child. Teacher and parents will collaborate to find some solutions in order to help the student. In this process, teacher has to tell student's parents the condition of their child at school. On the other hand, parents also have to share the information about what happens to their child at home. After sharing the information, both teacher and parents may find the solution to solve the problem. On the contrary, teachers and parents can combine their ideas and decide the best solution. In other words, between teachers and parents respect each other based on their roles and always work together for the development of children.

\section{THE CRITIQUE OF PLAN}

This behaviour management plan will be evaluated by looking at the strengths and the weaknesses. The first strength of the plan is collaborating with parents. It is strrongly believed that if there is a partnership between teachers and parents, they will succeed to meet students' needs. Moreover, both teachers and parents will be easier in handling students' problem because they have collaborated in sharing responsibilities. However, there is also a weakness of this plan. The use of time out as the intervention has become a critique in this plan.This intervention will not be effective because the primary school where this study is conducted does not have a special room. So, if teachers have a problem with disruptive student, they will send the student to principal's room. And the biggest problem is teachers' room is also at the same place as the principal's room. So that, this intervention will not work effectively in this plan.

There are some difficuties in writing this behaviour management plan, such as the physical environment of school. Seating arrangement in this primary school is very monotonous. Consequently, teachers can not vary the activities in the class such as in group work or in pairs because the chairs and tables position cannot be changed. This school is still using traditional chairs and desks. Besides seating arrangement, the numbers of students are also the problem in writing this plan. Normally, the school has 40 students in each class. So, teachers do not have enough space to teach the students. Furthermore, this school lacks of facilities to support learning and teaching process such as they do not have many materials to vary the activities in the class. The private school only has a small library and limited books.

In conclusion, it is believed that meeting students' needs, teacher-student status, and the role of teacher are the most important factors in managing misbehaviour students. And there are some preventive approaches in reducing inappropriate behaviour such as establish classroom climate includes classroom work and physical environment, communication between teacher and students and collaborating with parents. Besides the preventions, there are also some interventions if the preventions do not work for instance the use of natural or logical consequences, the use of time out and contacting parents. Also there are some critiques of this plan like the use of time out in the primary school is not effective, the difficulty of seating arrangement, the number of students and no space for teachers to teach. In contrast, collaborating with parents is the best step in this plan. It is expected that the school can provide more learning facilities for students and also material resources for teachers in the future.

\section{REFERENCES}

[1] Porter, L. (2000).Student Behaviour: Theory and Practice for Teachers. ( $2^{\text {nd }}$ ed.).

[2] Balson, M.(1988).Understanding Classroom Behaviour (2 ${ }^{\text {nd }}$ ed.).Australia: Allen \& Unwin Pty Ltd.

[3] Lucas, B. (1989). In Education Department of South Australia. Adler and Dreikurs: Theory and Practice. School Discipline: The 
management of student Behaviour: Implementation Kit. (pp.5-6). South Australia: The Publication Branch.

[4] Dillon, G., Muir, G., \& Giles, J. (1989). In Education Department of South Australia. Teaching Responsible Behaviours: One School's Approach. School Discipline: The Management of Student Behaviour: Implementation Kit. (pp.102-106). South Australia: The Publication Branch.

[5] Turney, C., Hatton, N., Laws, K., Sinclair, K. \& Smith, D. (1992). Educational Management Roles and Tasks: The Classroom Manager. Australia: Allen \& Unwin Pty Ltd.

[6] Konza, D., Grainger, J., \& Bradshaw, K. (2001). Classroom Management: A Survival Guide. Katoomba NSW: Social Sciences Press.

[7] Gordon, T. (1989). Teaching Children Self-Discipline. The United States: Times Books.

[8] William, P.A., Alley, R.D., \& Henson, K.T. (1999). Managing Secondary Classroom: Principles and Strategies for Effective Management and Instruction. The United States of America: Allyn \& Bacon.

[9] Johns, B.H \& Carr, V.G. (1995). Techniques for Managing: Verbally and Physically Aggressive Students. The USA: Love Publishing Company.

[10] Munn, R. (1989). In Education Department of South Australia. Involving Parents and families in Decision Making. School Discipline: The management of student Behaviour: Implementation Kit. (pp.42-47). South Australia: The Publication Branch.

[11] Glasser, W. (1977). Ten Steps to Good Discipline. Today's Education, 66, 61-63. 